\title{
Predictive thermodynamics for condensed phases $\dagger$
}

\author{
Leslie Glasser*a and H. Donald Brooke Jenkins*b \\ Received 14th July 2005 \\ First published as an Advance Article on the web 1st September 2005 \\ DOI: $10.1039 / \mathrm{b501741f}$
}

Thermodynamic information is central to assessment of the stability and reactivity of materials. However, because of both the demanding nature of experimental thermodynamics and the virtually unlimited number of conceivable compounds, experimental data is often unavailable or, for hypothetical materials, necessarily impossible to obtain. We describe simple procedures for thermodynamic prediction for condensed phases, both ionic and organic covalent, principally via formula unit volumes (or density); our volume-based approach (VBT) provides a new thermodynamic tool for such assessment. These methods, being independent of detailed knowledge of crystal structures, are applicable to liquids and amorphous materials as well as to crystalline solids. Examples of their use are provided.

\section{Introduction}

Thermodynamics owes its present form thanks to the genius of Josiah Willard Gibbs, a determinedly obscure and unassuming Yale professor of mathematical physics, who also laid the foundations of both vector analysis and of statistical mechanics. He developed thermodynamics into such a precise and workable format that very little of the basic theory has

${ }^{a}$ Nanochemistry Research Institute, Dept. of Applied Chemistry, Curtin University of Technology, GPO Box U1987, Perth WA, 6845, Australia. E-mail: l.glasser@exchange.curtin.edu.au; Fax: +61 89266 4699; Tel: +61862931202

${ }^{b}$ Department of Chemistry, University of Warwick, Coventry, West Midlands, UK CV4 7AL.E-mail: Don.Jenkins@warwick.ac.uk; Fax: +44 2476 466747; Tel: +44 2476 523265; +44 2476466747

$\uparrow$ Electronic supplementary information (ESI) available: Table S1 lists correlations developed by Westwell et al. ${ }^{7}$ Table S2 lists parameters for evaluation of lattice energy $U_{\text {POT }}$. Table S3 lists parameters for evaluation of entropies: (a) for inorganic solids and hydrates; (b) for minerals and (c) for organic solids and liquids. A number of further examples of the application of VBT methods is also available. In addition, there is provided an extensive list of current sources of thermodynamic data as well as a bibliography of recent parameterised group methods. See http://dx.doi.org/10.1039/b501741f needed to be changed subsequently or to any degree. While the subject retains its prominence and importance in the $21 \mathrm{st}$ century, emphasis has now shifted somewhat from a desire to understand existing processes towards a need to predict thermodynamic outcomes for newer materials. The compounds involved may represent the first examples of exciting new compounds with all the promise of displaying unusual or new chemical or physical properties to form the basis of modern materials science but, for such materials, we often have no thermodynamic information whatsoever-and therein lies the challenge. Some of these materials may be potential targets for synthetic endeavours, and different possible routes may need to be explored, for which thermodynamics provides guidance, as is outlined in the following tutorial review.

Thermodynamics has two faces: its theoretical face deals with relationships between thermal properties, such as the relation between entropy, $S$, and heat capacity, $C_{v}$ or $C_{p}$ :

$$
\begin{gathered}
\mathrm{d} S=\left(C_{v} / T\right) \mathrm{d} T+(\alpha / \kappa) \mathrm{d} V \\
\mathrm{~d} S=\left(C_{p} / T\right) \mathrm{d} T-V \alpha \mathrm{d} p
\end{gathered}
$$

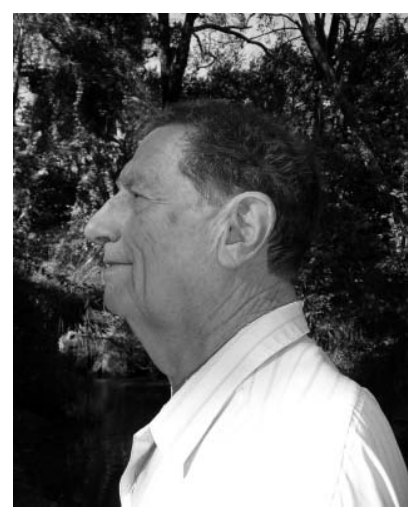

Leslie Glasser
Leslie Glasser is South African born with a first degree with distinction, in Industrial Chemistry, from Cape Town followed by a PhD and DIC from London. His project subject of proton conduction was later reviewed in Chem. Rev. He returned to South Africa first as Lecturer in Physical Chemistry at the University of the Witwatersrand ('Wits') and then as Professor at Rhodes University and, from 1980, at Wits. He retired in 2000 as Professor Emeritus and moved to Perth in Western Australia, where he is now Adjunct Research Professor.

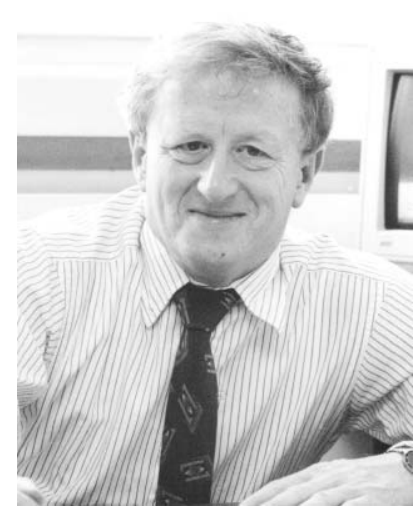

H. Donald Brooke Jenkins
Don Jenkins graduated from UMIST, receiving a DPhil degree from the University of Sussex. He immediately accepted a post at the, then, new University of Warwick, where he is now Professor in the Department of Chemistry. At Warwick he worked alongside Tom Waddington pioneering the development of the energetics associated with solid state chemistry. Recently (together with Leslie Glasser and Jack Passmore) he founded the VBT approach to thermodynamics. He is married to Sheila Anne and has three children and two grandchildren. 
where $\alpha=$ coefficient of cubic thermal expansion:

$$
\left(\frac{\partial V_{\mathrm{m}}}{\partial T}\right)_{p}=V_{\mathrm{m}} \alpha
$$

and $\kappa=$ coefficient of isothermal compressibility:

$$
\left(\frac{\partial V_{\mathrm{m}}}{\partial p}\right)_{T}=-V_{\mathrm{m}} \kappa
$$

while its experimental face deals with the data, such as the heat capacities and corresponding coefficients which are required in order to calculate an entropy. This data may be supplemented by statistical and quantum mechanics or by empirical modelling, which provide theoretical approaches for generating data. In this way, extensive data tables ${ }^{1,2}$ have been generated by thermodynamics practitioners, so providing the raw basis on which thermodynamics is applied.

Unfortunately, there are severe limitations in data generation, both in the exacting nature of experimental thermodynamics (coupled with its general demise as a "worthwhile" pursuit, which has seen the closure of numerous first rate thermochemical laboratories in recent decades!) as well as the nearly unlimited number of atom combinations which are available for generating conceivable compounds. Consequently, there is no possibility of ever producing a comprehensive set of tables of experimental data, even after excluding the fact that such tables cannot contain experimental data for materials which have not yet been prepared!

Nevertheless, assessment of the thermodynamic feasibility of the potential preparative reactions that might produce new materials and of their energetics, prior to an actual synthesis, remains as ever an attractive goal. The remedies available to tackle such a problem are either the application of theoretical procedures or development of reliable predictive methods by which these target data can be produced for materials in advance of their preparation. ${ }^{3}$ This situation is akin to problems currently involved in protein structural studies. There, the ease of DNA base-pair sequencing (from which protein sequences may be trivially derived using the genetic code of a triplet of base pairs encoding for each amino acid residue) as contrasted with the experimental difficulty of determining the folded structure of the protein, means that theoretical, predictive methods are needed and must be sought in order to generate the native structures of the folded proteins.

The present review is a tutorial presentation of simple, additive, empirical methods of thermodynamic prediction for condensed phases, with emphasis on volume-based methods, rather than consideration of the more theoretical procedures best suited to application and use by skilled practitioners. These simple predictive thermodynamic methods have been in use (although for limited purposes) for a considerable time. As a pertinent example, all undergraduates are taught the application of bond energy/enthalpy rules, whereby the internal energy, $U$ (or enthalpy, $H$ ), of a compound is treated as the sum of the energies of its constituent bonds, so that the energy of a gas phase reaction can be estimated as the difference of the energies of the bonds broken and formed during the reaction.

Beyond such simple bond energy procedures, more sophisticated and reliable group energy methods are available which have contributed considerably to improved understanding of reaction thermodynamics. Indeed, the capability of theoretical thermodynamic predictions for complex inorganic gas-phase materials, using ab initio molecular orbital procedures, has developed apace in recent years, notably for prediction of enthalpies of formation, adiabatic electron affinities, and ionisation potentials, without reliance on embedded parameters. 4

The required analysis is further complicated by the fact that kinetic considerations may (and often do) feature in the conclusions to be reached, but this will necessarily be ignored in the present context.

For a full understanding of the thermodynamics of materials, it is necessary also to have access to their entropies, $S$, which, together with the enthalpies, $H$, yield the Gibbs energies, $G$, from which thermodynamic prediction may be made. Although the empirical rules developed by Latimer gave an early impetus, together with other later developments, ${ }^{5}$ entropy prediction has been, in general, a more intractable problem than that of energy/enthalpy prediction and so, for undergraduates, is sometimes left simply at statements that entropies of larger, more mobile molecules are greater than entropies of molecules which are smaller and less mobile. Again, more sophisticated methods are available, based on statistical mechanical analysis of the energy levels accessible to the molecular system, and so most readily applicable to molecules in the gas phase. Correspondingly, knowledge of the phonon spectrum of a solid can permit calculation of its heat capacity and/or entropy.

Even given these powerful procedures, there is a clear need for simple, straight-forward predictive thermodynamic methods for general use which will, for example, permit deeper understanding of chemical synthetic and stability questions, such as: why do some procedures form the desired products, while others do not; will an hitherto unprepared material be stable; what energy is released during the decomposition of a selected material?

\section{Classification of additive predictive methods}

The methods of predictive thermodynamics are often additive approximations, based on summation of the values of properties of components of the system under consideration, and we will focus on such methods. We have developed a classification of additive methods as in Fig. 1, with the higherorder approximations requiring correspondingly larger numbers of empirical parameters for their summation (by contrast, an earlier classification ${ }^{6}$ was couched in different terms).

For the purposes of classification we propose that a zero order approximation is system based - such as focussing on the class of inorganic solids - and (seemingly paradoxically!) independent of any molecular parameters. Examples of such additivity approximations are: Dulong and Petit's rule for the molar heat capacities of monatomic metals $\left(C_{p} \sim 25 \mathrm{~J} \mathrm{~K}^{-1} \mathrm{~mol}^{-1}\right)$; Trouton's rule for the entropy of boiling-point $\left(T_{\mathrm{b}}\right)$ vaporization of organic molecules $\left(\Delta_{\text {vap }} S \sim\right.$ $90 \mathrm{~J} \mathrm{~K}^{-1} \mathrm{~mol}^{-1}$, also implying that $\left.\Delta_{\mathrm{vap}} H \sim 90 T_{\mathrm{b}}\right)$; Richards's rule for the entropy of fusion of rigid spherical molecules $\left(\Delta_{\text {fus }} S \sim 7-14 \mathrm{~J} \mathrm{~K}^{-1} \mathrm{~mol}^{-1}\right)$; Walden's rule for the 


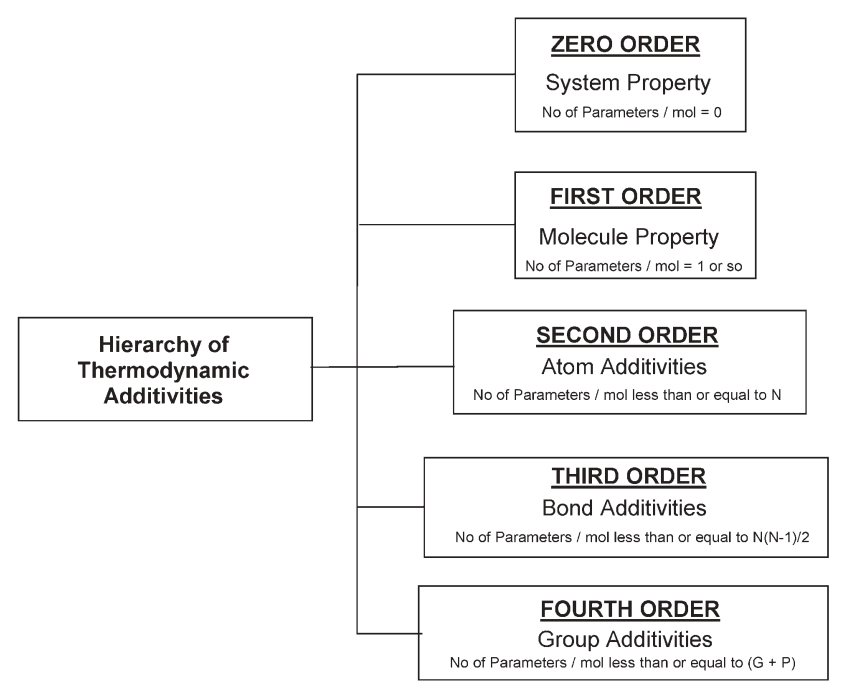

Fig. 1 Hierarchy of thermodynamic additivity methods. Note that as we descend the diagram the number of parameters required to be specified per molecule increases. $N=$ number of atoms; $G=$ number of groups; $P=$ number of group-interaction parameters.

entropy of fusion of rigid non-spherical molecules $\left(\Delta_{\text {fus }} S \sim\right.$ 20-60 $\left.\mathrm{J} \mathrm{K}^{-1} \mathrm{~mol}^{-1}\right)$; and Westwell et al.'s correlations ${ }^{7}$ between sublimation $\left(\Delta_{\text {sub }} H\right)$ and vaporization $\left(\Delta_{\text {vap }} H\right)$ enthalpies and melting, $T_{\mathrm{m}}$, and boiling, $T_{\mathrm{b}}$, temperatures (see Table S1, in the electronic supplementary information $($ ESI $) \dagger$ - as well as a host of others. ${ }^{5}$ The only information required for application of a zero order approximation is that of the general nature of the species involved in the prediction. The approaches in this category are not simply "rules of thumb" since they generally have a sound theoretical basis.

A first order approximation depends on a single property possessed by the set of atoms comprising the chemical unit under study; for example, molar entropies are found to vary quite closely linearly with molar volumes. ${ }^{8,9}$ An important consideration is that these first order methods are independent of details of the relative placement of the species, because they invoke only properties of the molecular entity as a whole. An implication of this simplifying assumption is that the procedures should apply equally well to materials in any condensed phase (crystal, liquid or amorphous). These first order approximations are now known to be of particular significance since the properties of mixed systems are themselves additive: the lattice energies of ionic materials are weighted sums of the lattice energies of their "constituent" materials (e.g., fluoroapatite, $\mathrm{Ca}_{5}\left(\mathrm{PO}_{4}\right)_{3} \mathrm{~F}$, may be taken to consist of $1 / 2 \mathrm{CaF}_{2}+3 / 2 \mathrm{Ca}_{3}\left(\mathrm{PO}_{4}\right)_{2}$ to a first order approximation). ${ }^{10-12}$

A second order approximation corresponds to the additivity of atomic (or ionic) properties; some properties which can be evaluated on this basis are molar mass (which, in chemical terms, is an exact atom summation, but is less successful for purposes of nuclear physics); molar volume (as in the case of atom $^{13}$ or ion additivities, ${ }^{14}$ or our isomegethic rule $^{15}$ - see below); atomic heat capacity (Neumann-Kopp rule); ${ }^{5}$ and magnetic susceptibility. ${ }^{14}$

A third order approximation corresponds to the additivity of local linkages, such as chemical bonds. As previously mentioned, enthalpies of reaction can be estimated by reference to differences between the enthalpies of bonds ${ }^{2}$ formed and bonds destroyed during the course of a reaction.

The most complex (and also most extensively developed) of the additivity methods is that of fourth order: the group additivity methods. ${ }^{16}$ Group methods rely on the identification of groups (such as methyl, hydroxyl, etc.) within molecular species, and evaluation of parameters relating to these groups which are transferable for the property concerned. Examples $^{3,5,6}$ are group additivities for: heat capacities; energies (and enthalpies) of formation; absolute entropies; enthalpies and entropies of fusion, vaporization and dissolution; molar volumes (and, hence, densities); and many others, too many to reference in the present limited review.

As has been noted above, increasing order in this classification implies involvement of increasing numbers of the associated empirical parameters. Thus, for atomic properties (being of second order), a property value (such as mass) is required for each element in the periodic table, while bond additivities (of third order) require values for each of the many bond types which go towards pairing elemental contributions. Group properties (fourth order) require not only parameters for each type of group but also for their varying steric and even electronic interactions. Accordingly, group property tables accompanying such methods inevitably contain many fitted parameters. Furthermore, such group properties have largely been developed for gas phase systems, while similar properties of condensed phases have been neglected. However, there are also extensive tables and group methods for prediction of sublimation thermodynamics ${ }^{17}$ which can be paired with the gas-phase predictions to yield properties for the condensed phase.

The power of any method used in predictive thermodynamics is governed by several factors. These include the scope and versatility of the method (i.e., the number and variety of thermodynamic systems-real, counterintuitive or even hypothetical - that can usefully be treated by it); the simplicity of the approach (i.e., the order of the approximation required, $c f$. Fig. 1, where the lower the order, the more the approach is oriented towards everyday use); the feasibility of the approach (i.e., whether the necessary parameters/data are either available or capable of estimation); and the reliability of the values thereby predicted. In our "volume-based" thermodynamics approach, ${ }^{18,19}$ we believe that we have optimised the above four criteria to produce an approach which is amenable to the exploration of the thermodynamics of new materials as well as being applicable to more traditional compounds.

\section{Calculation procedure}

As is typical of any maturing subject, chemistry is increasingly quantitative in nature. Thus, if today's inorganic chemist is faced with a possible choice of synthetic routes by which to prepare a new material, s/he might well wish to explore their thermodynamic feasibilities (i.e., determine the magnitude and sign of $\Delta G$ for each route). The main problem here is the need to acquire the necessary thermodynamic data for the new material. The problem of estimating $\Delta G$ 


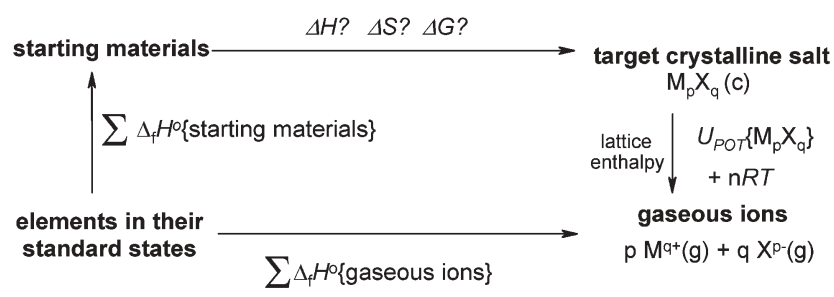

Fig. 2 Born-Haber-Fajans thermochemical cycle, which provides an alternative (i.e., indirect) route for the estimation of $\Delta H$ for the preparation of $\mathrm{M}_{p} \mathrm{X}_{q}(\mathrm{c})$.

for such reactions, where the data is unknowable, can be tackled from the standpoint of a thermochemical cycle (Fig. 2) using the subterfuge of introducing alternative steps in the cycle by which the estimation of data for the new material becomes possible by procedures outlined in this review.

$\Delta G$ for the target synthetic reaction is obtained, in principle, as the difference in the Gibbs energies of formation of the target salt and the sum of the Gibbs energies of formation of the starting materials (allowing also for the Gibbs energies of any other materials produced in the synthesis). However, since $\Delta_{\mathrm{f}} G^{\circ}\left\{\mathrm{M}_{p} \mathrm{X}_{q}, \mathrm{c}\right\}$ is almost certainly unknown (the target salt being an entirely new material) the direct route to obtain $\Delta G$ is not an option. We elect, therefore, to calculate $\Delta H$ from the above cycle using the equation:

$$
\begin{gathered}
\Delta H=\sum \Delta_{\mathrm{f}} H^{\circ}\{\text { gaseous ions }\}-U_{\mathrm{POT}}\left\{\mathrm{M}_{p} \mathrm{X}_{q}\right\}-\mathrm{n} R T- \\
\sum \Delta_{\mathrm{f}} H^{\circ}\{\text { starting materials }\}
\end{gathered}
$$

The quantity: $\sum \Delta_{\mathrm{f}} H^{\circ}$ \{gaseous ions\} may be obtained either from available literature data, if the ions are already known, or else by resort to an $a b$ initio computation (see ref. 20, for example). The quantity: $\sum \Delta_{\mathrm{f}} H^{\circ}$ \{starting materials\} is often known from standard data tables. The lattice enthalpy term consists of the lattice (potential) energy, $U_{\text {РОт }}\left\{\mathrm{M}_{p} \mathrm{X}_{q}\right\}$, and an appropriate number, $n$, of $R T$ terms, where there is added $\left(n_{\mathrm{M}} / 2-2\right) R T$ for each ion produced, where $n_{\mathrm{M}}=3$ for monatomic gaseous ions, 5 for linear polyatomic ions, and 6 for non-linear polyatomic ions. ${ }^{21}$ The lattice potential energy is a function of the assigned charge and $1 / V_{\mathrm{m}}{ }^{1 / 3}$, where $V_{\mathrm{m}}$ can be estimated by any of the routes shown in Fig. 3 .

The entropy change, $\Delta S$, for a target reaction can be estimated directly and without resort to a cycle since: $\Delta S=S_{298}{ }^{\circ}\left\{\mathrm{M}_{p} \mathrm{X}_{q}, \mathrm{c}\right\}-\Sigma S^{\circ}{ }_{298}\{$ starting materials $\}$. The standard entropy for the new material, $S_{298}{ }^{\circ}\left\{\mathrm{M}_{p} \mathrm{X}_{q}\right\}$, can be estimated (for details, see below, Table S3 in the ESI, $\uparrow$ and ref. 8,9) from:

$$
S_{298}{ }^{\circ}\left\{\mathrm{M}_{p} \mathrm{X}_{q}\right\}=\mathrm{k} V_{\mathrm{m}}\left\{\mathrm{M}_{p} \mathrm{X}_{q}\right\}+\mathrm{c}
$$
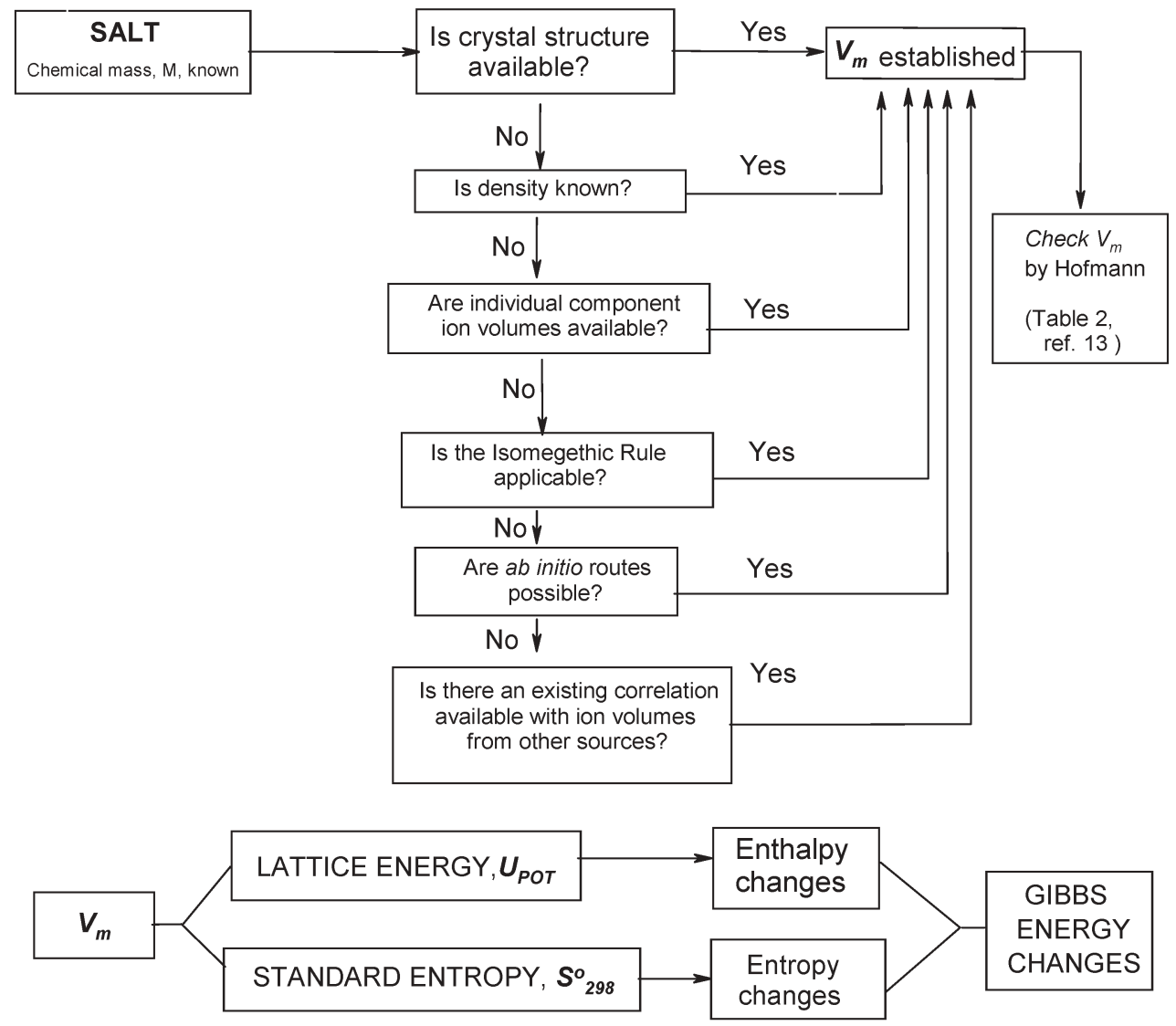

Fig. 3 Scheme for the determination of the formula unit volume, $V_{\mathrm{m}}$. The value obtained may be checked using the atomic data table of D. W. M. Hofmann. ${ }^{13}$ Determination of $V_{\mathrm{m}}$ then provides a route to thermodynamic data (as indicated in the lower half of the figure). 
Use of Latimer's rules ${ }^{5}$ for the estimation of $S_{298}{ }^{\circ}\left\{\mathrm{M}_{p} \mathrm{X}_{q}, \mathrm{c}\right\}$ would offer an alternative approach. $\Delta G$ is then calculated as $\Delta H-\mathrm{T} \Delta S$.

\section{Volume-based thermodynamics (VBT)}

We now consider how our first order methods may be applied to such thermodynamic prediction. The VBT method is easy to apply and can be used for a variety of problems, often leading to equations which have extremely simple forms. The key parameter, central to the approach, is that of formula unit volume, $V_{\mathrm{m}}$, and Fig. 3 conveniently summarises the various possible methods available for estimating such data. In most cases the procedure is self-explanatory, although additional notes appear below.

There are readily accessible tables ${ }^{22}$ of ionic and atomic radii, $r$, from which ionic volumes may be estimated $\left(=4 \pi r^{3} / 3\right.$, assuming the ions to be simple spheres). The use of volume as a size parameter ${ }^{14}$ instead of radius has the important advantage that it is more direct, permitting an improved representation of non-spherical ions.

If we know the unit cell volume, $V_{\text {cell }}$, and the number of molecules in the unit cell, $Z$, then $V_{\mathrm{m}}=V_{\text {cell }} / Z$. Alternatively, from the density, ${ }^{19} \rho / \mathrm{g} \mathrm{cm}^{-3}$, since densities are inversely related to molar volumes by a strict mathematical relation involving the Avogadro constant, we obtain:

$$
V_{\mathrm{m}} / \mathrm{nm}^{3}=1.66 \times 10^{-3}\left(M / \mathrm{g} \mathrm{mol}^{-1}\right) /\left(\rho / \mathrm{g} \mathrm{cm}^{-3}\right)
$$

If for solid $\mathrm{M}_{p} \mathrm{X}_{q}$ (for example), the individual ion volumes, $V\left\{\mathrm{M}^{q+}\right\}$ and $V\left\{\mathrm{X}^{p-}\right\}$ are known then by, ion volume additivity: ${ }^{18} V_{\mathrm{m}}\left\{\mathrm{M}_{p} \mathrm{X}_{q}\right\} \approx p V\left\{\mathrm{M}^{q+}\right\}+q V\left\{\mathrm{X}^{p-}\right\}$. The isomegethic rule ${ }^{15}$ is extremely powerful for generating ion and formula unit volumes, particularly for hypothetical materials or for those materials having no other data source (see Section 5 below). Another approach ${ }^{20}$ is to equate $V$ for an ion as the volume enclosed inside the 0.001 au electron density contour at B3LYP/6-31+G* level. The volumes yielded by different experimental procedures (e.g., those from solution rather than from solid state sources) are not necessarily equivalent, and each property must be studied for its own features. Thus, we have established ${ }^{14}$ the following relations among various classes of ionic volumes, using Marcus's ionic volumes, $V_{\mathrm{M}}$, (which are derived from ionic radii) as reference. ${ }^{23} V_{\mathrm{J}}$ here refers to Jenkins et al.'s volumes (which are the ion volumes referred to in this paper and included in our database ${ }^{18}$ ).

$$
\begin{aligned}
& \text { Cation volumes: } V_{\mathrm{J}} / \mathrm{nm}^{3} \approx(1.258 \pm 0.016) V_{\mathrm{M}} / \mathrm{nm}^{3} \\
& \text { Anion volumes: } V_{\mathrm{J}} / \mathrm{nm}^{3} \approx(1.342 \pm 0.041) V_{\mathrm{M}} / \mathrm{nm}^{3}+ \\
& (0.0205 \pm 0.028)
\end{aligned}
$$

Ionic refraction volumes: $\left(R_{\mathrm{D} /} N_{\mathrm{A}}\right) / \mathrm{nm}^{3} \approx$

$$
(0.594 \pm 0.005) V_{\mathrm{M}} / \mathrm{nm}^{3}
$$

Diamagnetic susceptibility volumes: $-10^{6} \chi m / N_{\mathrm{A}} \approx$ $(10.51 \pm 0.054) V_{\mathrm{M}} / \mathrm{nm}^{3}+(0.022 \pm 0.004)$

(Clearly, the latter two measures should be taken simply as empirical correlations.)
In a survey of 182239 crystal structures from the Cambridge Structural Database (CSD), Hofmann ${ }^{13}$ derived average volumes (in $\AA^{3}=10^{3} \mathrm{~nm}^{3}$ ) for the elements, as listed in Table 2 of his paper. An account of local environment for certain atoms (i.e., C, H, N, O and F) is ideally needed to prescribe appropriate volumes in all circumstances (by adding a functional group dependence) and so volumes derived involving these atoms are not always reliable. In most cases, our ion additive volumes and those of Hofmann (although more suited to estimating the total $V_{\mathrm{m}}$ ) often agrees quite well and his approach can be used as an alternative source of volume generation for the VBT method (e.g., our volume database $^{17}$ gives $V\left\{\mathrm{Nb}_{2} \mathrm{OCl}_{10}{ }^{2-}\right\} / \mathrm{nm}^{3} \approx 0.353( \pm 0.015)$ for the ion whereas from Hofmann we have: $V\left\{\mathrm{Nb}_{2} \mathrm{OCl}_{10}{ }^{2-}\right\} / \mathrm{nm}^{3} \approx[2\{37( \pm 2)\}+11.39( \pm 0.17)+$ $10\{25.8( \pm 3)\}] / 1000=0.343( \pm 0.010))$.

\subsection{Enthalpies of condensed phases: ionics: lattice energy}

Prediction of the enthalpies of formation of ionic compounds often relies on evaluation of their lattice energies, $U_{\text {РОт }}$ (via the Born-Haber-Fajans cycle), this being the ionic equivalent of the enthalpy of evaporation. However, lattice energies for ionic materials cannot be measured experimentally because they involve separation into independent gas phase ions of the ions constituting the condensed phase, whereas ionic materials generally dissociate experimentally into neutral atoms or neutral atom groups. Theoretical calculations are possibleeither quantum or empirical modelling — but these are complex and time-consuming and often apply to relatively small systems. However, coulombic forces are dominating in ionic systems, and thus coulomb-based equations which predict lattice energies work rather well - generally to better than $5 \%$. Historically, the initial impetuses in this direction were the Born-Mayer and Born-Landé equations, as adapted by Kapustinskii and Yatsimirskii initially (and reviewed ${ }^{24} 50$ years ago next year in the predecessor to Chemical Society Reviews!) to represent binary ionic solids:

$$
U_{\mathrm{POT}}=\frac{A v\left|z_{+} z_{-}\right|}{\langle r\rangle}\left(1-\frac{\rho}{\langle r\rangle}\right)
$$

where $z_{+}, z_{-}$/electron units are the integer charges on the cations and anions, respectively, $v$ is the number of ions per formula unit, $\rho$ is a compressibility constant (usually chosen as $\rho=0.0345 \mathrm{~nm}),\langle r\rangle$ is the sum of the cation and anion thermochemical radii, and $A\left(=121.4 \mathrm{~kJ} \mathrm{~mol}^{-1} \mathrm{~nm}\right)$ is an electrostatic constant. Glasser ${ }^{25}$ generalized Kapustinskii's equation to ionic systems of essentially any complexity by the substitution:

$$
v\left|z_{+} z_{-}\right| \Rightarrow \sum_{i} n_{i} z_{i}^{2}=2 I
$$

where $I$ is the ionic strength factor of the formula unit, and $<r>$ becomes the weighted-mean ionic radius. The generalized lattice energy equation is then:

$$
U_{\mathrm{POT}}=\frac{2 A I}{\langle r\rangle}\left(1-\frac{\rho}{\langle r\rangle}\right)
$$

It is in this context that thermochemical radii are generated and used. 
Avoiding the unnecessary assumption of sphericity, we have more recently established ${ }^{18}$ the general lattice energy relation to the inverse-cube root of the formula unit volume, $V_{\mathrm{m}}$ :

$$
U_{\mathrm{POT}}=2 I\left(\frac{\alpha}{V_{\mathrm{m}}^{1 / 3}}+\beta\right)
$$

where $\alpha$ and $\beta$ are empirical constants (see Table S2 in the ESI $\dagger$ ), determined by fitting to extensive experimental data. The presence of the inverse cube root is convenient since it means that we can tolerate small errors in estimates of the volume, $V_{\mathrm{m}}$, without compromising the resultant lattice energy estimate.

The linear correlation for the above relation, eqn (12), applies satisfactorily only to lattice energies less than $5000 \mathrm{~kJ} \mathrm{~mol}^{-1}$, making it unsuitable for the more complex ionic materials, including most minerals. However, a limiting version of the equation (for $U_{\text {POT }}>5000 \mathrm{~kJ} \mathrm{~mol}^{-1}$ ), which contains no empirical constants whatsoever and yet satisfactorily predicts lattice energies beyond $5000 \mathrm{~kJ} \mathrm{~mol}^{-1}$ up to $70000 \mathrm{~kJ} \mathrm{~mol}^{-1}$ (and probably beyond), takes the form: ${ }^{26}$

$$
U_{\mathrm{POT}}=A I\left(2 I / V_{m}\right)^{1 / 3}
$$

From the relation of formula unit (or molecular) volume to density (see eqn (7)), the above equations can also readily be applied using densities, either experimental or estimated.

\subsection{Hydrate, $\mathrm{M}_{p} \mathrm{X}_{q} \cdot n \mathrm{H}_{2} \mathrm{O}$, and solvate, $\Delta_{\mathrm{f}} H^{\circ} \mathrm{M}_{p} \mathrm{X}_{q} \cdot \mathrm{nS}$ thermodynamics}

The lattice energies of hydrates, $U_{\text {РОт }}\left\{\mathrm{M}_{p} \mathrm{X}_{q} \cdot n \mathrm{H}_{2} \mathrm{O}\right\}$, on the other hand, are evaluated using equations based on our thermodynamic Difference Rules: ${ }^{10,11}$

$$
U_{\mathrm{POT}}\left\{\mathrm{M}_{p} \mathrm{X}_{q} \cdot n \mathrm{H}_{2} \mathrm{O}\right\}=U_{\mathrm{POT}}\left\{\mathrm{M}_{p} \mathrm{X}_{q}\right\}+n \theta_{U}\left\{\mathrm{H}_{2} \mathrm{O}\right\}
$$

where $\theta_{U}\left\{\mathrm{H}_{2} \mathrm{O}\right\}=54.3 \mathrm{~kJ} \mathrm{~mol}^{-1}$, as empirically determined. Lattice energies of solvates, $U_{\mathrm{POT}}\left\{\mathrm{M}_{p} \mathrm{X}_{q} \cdot n \mathrm{~S}\right\}$, in general can be obtained in a similar way:

$$
U_{\mathrm{POT}}\left\{\mathrm{M}_{p} \mathrm{X}_{q} \cdot n \mathrm{~S}\right\}=U_{\mathrm{POT}}\left\{\mathrm{M}_{p} \mathrm{X}_{q}\right\}+n \theta_{U}\{\mathrm{~S}\}
$$

It is important to note that eqn (12) does not return a value of $U_{\mathrm{POT}}\left\{\mathrm{M}_{p} \mathrm{X}_{q} \cdot n \mathrm{H}_{2} \mathrm{O}\right\}$ if $V_{\mathrm{m}}\left\{\mathrm{M}_{p} \mathrm{X}_{q} \cdot n \mathrm{H}_{2} \mathrm{O}\right\}$ is substituted for $V_{\mathrm{m}}$, since lattice energies are not simply additive as are the volumes (see Scheme 3 in ref. 10, offering guidance as to which equations are appropriate to use in various circumstances).

The Difference Rule has also provided a more extensive set of thermodynamic relationships, of the form:

$$
\begin{gathered}
{[P\{n \text {-solvate }\}-P\{\text { parent }\}]=n \theta_{P}\{\mathrm{~S}, \mathrm{~s}-\mathrm{s}\}} \\
{\left[P\{n \text {-solvate }\}-P\left\{n^{\prime} \text {-solvate }\right\}\right] /\left(n-n^{\prime}\right)=\theta_{\mathrm{P}}\{\mathrm{S}, \mathrm{s}-\mathrm{s}\}}
\end{gathered}
$$

where $P=\Delta_{\mathrm{f}} H^{\circ}, \Delta_{\mathrm{f}} G^{\circ}, \Delta_{\mathrm{f}} S^{\circ}$ or $S_{298}{ }^{\circ}$ (in addition to $U_{\text {POT }}$ and $V_{\mathrm{m}}$ ) both solvate and parent being in the solid (condensed) state, s-s, such that it is only necessary to know pairs of values $P$ \{parent $\}$ and $P$ \{n-solvate $\}$ or else $P$ nn-solvate $\}$ and $P\left\{\mathrm{n}^{\prime}\right.$-solvate $\}$ in order to be able to estimate either the remaining data for all hydrates in the series or for all the solvates and the missing parent $\left(\mathrm{M}_{p} \mathrm{X}_{q}\right)$ value. Values of $\theta_{P}\{\mathrm{~S}, \mathrm{~S}-\mathrm{S}\}$ have been established ${ }^{11}$ for the following: $\mathrm{S}=\mathrm{H}_{2} \mathrm{O}$ (hydrates) $\left(P=\Delta_{\mathrm{f}} H^{\circ}, \Delta_{\mathrm{f}} G^{\circ}, \Delta_{\mathrm{f}} S^{\circ}, S_{298}^{\circ}, U_{\text {POT }}\right.$ and $\left.V_{\mathrm{m}}\right) ; \mathrm{D}_{2} \mathrm{O}$ $\left(P=\Delta_{\mathrm{f}} H^{\circ}\right) ; \mathrm{NH}_{3}\left(P=\Delta_{\mathrm{f}} H^{\circ}, \Delta_{\mathrm{f}} G^{\circ}, \Delta_{\mathrm{f}} S^{\circ}, S_{298}^{\circ}\right) ; \mathrm{ND}_{3}$ $\left(P=\Delta_{\mathrm{f}} H^{\circ}, \Delta_{\mathrm{f}} G^{\circ}, \Delta_{\mathrm{f}} S^{\circ}, S_{298}^{\circ}\right) ;\left(\mathrm{CH}_{3}\right)_{2} \mathrm{O}\left(P=\Delta_{\mathrm{f}} H^{\circ}, \Delta_{\mathrm{f}} G^{\circ}, \Delta_{\mathrm{f}} S^{\circ}\right.$, $\left.S_{298^{\circ}}\right) ; \mathrm{NaOH}\left(P=\Delta_{\mathrm{f}} H^{\circ}\right) ; \mathrm{CH}_{3} \mathrm{OH}\left(P=\Delta_{\mathrm{f}} H^{\circ}\right) ; \mathrm{C}_{2} \mathrm{H}_{5} \mathrm{OH}$ $\left(P=\Delta_{\mathrm{f}} H^{\circ}\right) ;\left(\mathrm{CH}_{2} \mathrm{OH}\right)_{2}\left(P=\Delta_{\mathrm{f}} H^{\circ}\right) ; \mathrm{H}_{2} \mathrm{~S}\left(P=\Delta_{\mathrm{f}} H^{\circ}\right)$ and $\mathrm{SO}_{2}$ $\left(P=\Delta_{\mathrm{f}} H^{\circ}\right)$.

\subsection{Entropies of condensed phases. Standard entropies, $S_{298}$}

One of the set of six Maxwell relations can be derived from eqns (1) and (2), namely:

$$
\left(\frac{\partial S}{\partial V_{\mathrm{m}}}\right)_{T}=\left(\frac{\partial p}{\partial T}\right)_{V}=\frac{\alpha}{\kappa}
$$

Since $\alpha / \kappa$ is approximately constant for condensed phases of similar type (whether ionics or organics), this equation suggests that entropy is linearly correlated with formula unit (molar) volume. We have found that the correlation implied is obeyed rather well over sets containing hundreds of ionic materials $^{8}$ (Fig. 4 and Table S3a in the ESI $\dagger$ ), minerals ${ }^{8}$ ( Table $\mathrm{S} 3 \mathrm{~b} \dagger$ ), and thousands of organic liquids and solids ${ }^{9}$ ( Table S3c $\dagger$ ). We have observed no systematic violations of these correlations (at this level of approximation) among any of the materials studied.

We ascribe the reliability of these correlations to the fact that the derivative $(\partial p / \partial T)_{V}$ represents the increase in pressure, $p$ (at fixed volume, $V$ ), arising from a rise in absolute temperature, $T$. This increase in pressure results from attempts at reduction in the intermolecular spaces (rather than of the excluded volumes of the molecular groups themselves, which are largely incompressible) against the intermolecular forces, where forces acting in the intermolecular spaces are similar within a given group of materials.

Specializations for groups of related materials ( Table S3a of the ESI $\dagger$ ) should be studied if greater accuracy is required. For silicate minerals ( Table S3b of the ESI $\dagger$ ), for example, the very simple linear correlation against formula unit volume can be improved by adopting different entropy/volume parameters

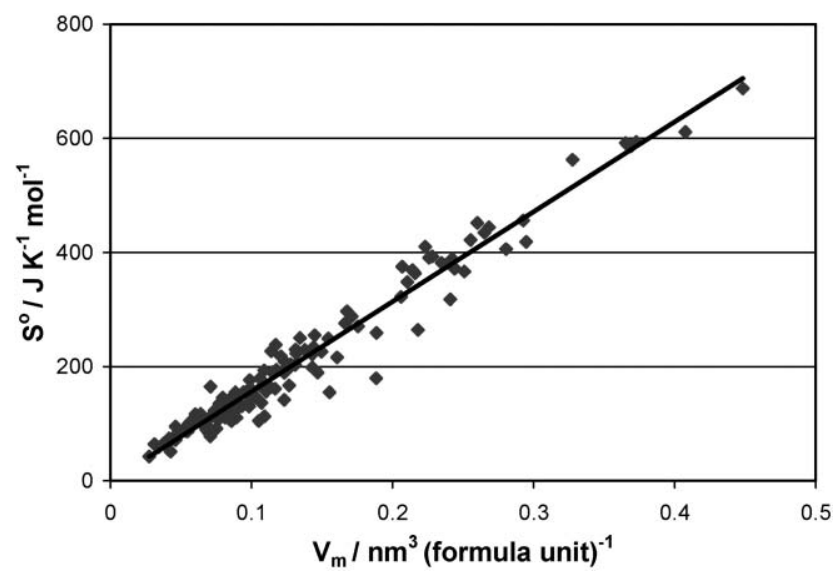

Fig. $4 S_{298} / \mathrm{J} \mathrm{K}^{-1} \mathrm{~mol}^{-1}$ plotted versus formula unit volume, $V_{\mathrm{m}}$, for 137 anhydrous and hydrated inorganic salts. See Table S3a in the ESI $\dagger$ for regression parameters. 
for each different coordination site within the mineral - this, of course, implies that the mineral structure is known (or guessed), which is not required for the linear correlation.

\section{The isomegethic $\left(\mu \varepsilon \gamma \varepsilon \theta \sigma_{\varsigma}\{\right.$ megethos $\}=$ size $)$ rule ${ }^{15}$}

The recently-developed and extremely powerful isomegethic rule is used for the estimation of ion volumes and is formulated as follows:

Ionic salts of the same chemical formula and, with very few exceptions, having identical charge states (i.e., lattice ionic strength factors, $I$ ), will have approximately equal formula unit volumes, $V_{\mathrm{m}}$.

Immediately, since their volumes are approximately equal, so also (according to relations and correlations already considered) will be their densities, $\rho$, lattice potential energies, $U_{\text {POT }}$, and standard absolute entropies, $S_{298^{\circ}}$.

We choose the estimation of volume data for $\mathrm{S}_{2}{ }^{+}$salts as an example of the application of the isomegethic rule. The volume is needed for $\mathrm{S}_{2}{ }^{+}$, but no salts of this cation have ever been prepared, so there is neither crystal structure data nor density information available, nor are there species of the ion in solution which might provide correlations ${ }^{14}$ with the solid state. This leaves us (see Fig. 3) with the choice of using $a b$ initio or isomegethic routes. The isomegethic rule provides estimates by approximating:

$$
V\left\{\mathrm{~S}_{2}{ }^{+}\right\} \approx 1 / 2 V\left\{\mathrm{~S}_{4}{ }^{2+}\right\}
$$

or

$$
V\left\{\mathrm{~S}_{2}{ }^{+}\right\} \approx V\left\{\mathrm{~S}_{2} \mathrm{~N}^{+}\right\}+V\left\{\mathrm{O}_{2}{ }^{-}\right\}-V\left\{\mathrm{NO}_{2}{ }^{-}\right\}
$$

Since there are salts of the $\mathrm{S}_{4}{ }^{2+}$ and $\mathrm{S}_{2} \mathrm{~N}^{+}$cations, with crystal structure data available so that both $V\left\{\mathrm{~S}_{4}{ }^{2+}\right\}$ and $V\left\{\mathrm{~S}_{2} \mathrm{~N}^{+}\right\}$may be estimated and, since both $V\left\{\mathrm{O}_{2}{ }^{-}\right\}$and $V\left\{\mathrm{NO}_{2}{ }^{-}\right\}$appear in our database, ${ }^{18}$ we can obtain $V\left\{\mathrm{~S}_{2}{ }^{+}\right\}$ and proceed.

Other relationships (by no means exhaustive) which can be invoked using the rule are illustrated by the following diverse examples:

$$
V\left\{\mathrm{Ti}_{4} \mathrm{~F}_{18}^{2-}\right\} \approx 4 V\left\{\mathrm{TiF}_{4}\right\}+2 V\left\{\mathrm{~F}^{-}\right\}
$$

here involving a neutral molecular species, or for the species $\mathrm{NO}_{x}$ and $\mathrm{ClO}_{y}$, which can occur either as cations or anions:

$$
\begin{gathered}
V_{\mathrm{m}}\left\{\mathrm{NO}_{x}^{+} \mathrm{ClO}_{y}{ }^{-}\right\} \approx V_{\mathrm{m}}\left\{\mathrm{NO}_{y}^{+} \mathrm{ClO}_{x}{ }^{-}\right\} \approx \\
V_{\mathrm{m}}\left\{\mathrm{ClO}_{y}{ }^{+} \mathrm{NO}_{x}{ }^{-}\right\} \approx V_{\mathrm{m}}\left\{\mathrm{ClO}_{x}{ }^{+} \mathrm{NO}_{y}{ }^{-}\right\}
\end{gathered}
$$

Numerous examples of the application of the rule for different species and properties have been presented. ${ }^{15}$

\section{Quantitative predictions for thermodynamic data using VBT}

If there ever was a field where thermodynamic data are difficult to come by experimentally it is that of inorganic fluorine chemistry - for the obvious reasons of the instability of the compounds, their tendency to be hygroscopic or to hydrolyse in solution, and their inherent reactivity or tendency to spontaneously detonate, and other properties. It is not surprising therefore that it was partly within this area that our method found its origins, as a response to the practical problems and needs of experimentalists. Thus, in probing this area our method found useful application in generating quantitative thermochemical data which has been subsequently verified by ab initio calculation. ${ }^{27}$ Another pertinent example of the application of our procedures is in the study of complex inorganic reaction systems, where reactions in the electrochromic Prussian Blue system have been successfully elucidated. ${ }^{28}$ Exploration continues both in fluorine chemistry, as in other branches of chemistry.

Example application: use of VBT to probe the thermodynamics of the decomposition mode of the (hypothetical) material $\mathrm{N}_{5}{ }^{+} \mathrm{N}_{3}{ }^{-}$

The question has recently arisen ${ }^{20}$ as to whether solid $\mathrm{N}_{5}{ }^{+} \mathrm{N}_{3}{ }^{-}$ (and indeed $\mathrm{N}_{5}{ }^{+} \mathrm{N}_{5}{ }^{-}$) can be a stable allotrope of nitrogen. We consider the former question here. From the cycle:

$$
\begin{aligned}
& U_{P O T}\left\{\mathrm{~N}_{5}{ }^{+} \mathrm{N}_{3}^{-}\right\}+3 / 2 R T \mathrm{~N}_{5}+\mathrm{N}_{3}^{-}(\mathrm{s}) \stackrel{\Delta H, \Delta S, \Delta G}{\longrightarrow} 4 \mathrm{~N}_{2}(\mathrm{~g}) \\
& \Delta H / \mathrm{kJ} \mathrm{mol}^{-1}=U_{\mathrm{POT}}\left\{\mathrm{N}_{5}{ }^{+} \mathrm{N}_{3}{ }^{-}\right\}+3 / 2 R T- \\
& \Delta_{\mathrm{f}} H^{\circ}\left\{\mathrm{N}_{5}{ }^{+}, \mathrm{g}\right\}-\Delta_{\mathrm{f}} H^{\circ}\left\{\mathrm{N}_{3}{ }^{-}, \mathrm{g}\right\}
\end{aligned}
$$

and taking $\Delta_{\mathrm{f}} H^{\circ}\left\{\mathrm{N}_{5}{ }^{+}, \mathrm{g}\right\}=1478.6 \mathrm{~kJ} \mathrm{~mol}^{-1}$ and $\Delta_{\mathrm{f}} H^{\circ}\left\{\mathrm{N}_{3}{ }^{-}, \mathrm{g}\right\}=197.5 \mathrm{~kJ} \mathrm{~mol}^{-1}$ (as estimated by ab initio routes $^{26}$ and close to the value earlier obtained by Jenkins, ${ }^{29}$ so finally resolving an ongoing uncertainty):

$$
\Delta H / \mathrm{kJ} \mathrm{mol}^{-1}=U_{\text {РОТ }}\left\{\mathrm{N}_{5}^{+} \mathrm{N}_{3}{ }^{-}\right\}-1672.4
$$

and taking $S_{298}{ }^{\circ}\left\{\mathrm{N}_{2}, \mathrm{~g}\right\} / \mathrm{J} \mathrm{K}{ }^{-1} \mathrm{~mol}^{-1}=191.6$, then:

$$
\Delta S / \mathrm{J} \mathrm{K}^{-1} \mathrm{~mol}^{-1}=766.5-S_{298}{ }^{\circ}\left\{\mathrm{N}_{5}{ }^{+} \mathrm{N}_{3}{ }^{-}\right\}
$$

$V\left\{\mathrm{~N}_{5}{ }^{+}\right\}$can be estimated from the volume of the reported crystal structure ${ }^{30}$ of $\mathrm{N}_{5} \mathrm{Sb}_{2} \mathrm{~F}_{11}$ by assuming that:

$$
\begin{gathered}
V\left\{\mathrm{~N}_{5}{ }^{+}\right\} / \mathrm{nm}^{3} \approx V_{\mathrm{m}}\left\{\mathrm{N}_{5} \mathrm{Sb}_{2} \mathrm{~F}_{11}\right\}-V\left\{\mathrm{Sb}_{2} \mathrm{~F}_{11}{ }^{-}\right\} \approx \\
0.051( \pm 0.020)
\end{gathered}
$$

taking $V\left\{\mathrm{Sb}_{2} \mathrm{~F}_{11}{ }^{-}\right\} / \mathrm{nm}^{3}=0.227 \quad( \pm 0.020) .{ }^{18}$ Since $V\left\{\mathrm{~N}_{3}{ }^{-}\right\} / \mathrm{nm}^{3}=0.058( \pm 0.014)$ from our database ${ }^{18}$ then: hence, $V_{\mathrm{m}}\left\{\mathrm{N}_{5}{ }^{+} \mathrm{N}_{3}{ }^{-}\right\} / \mathrm{nm}^{3} \approx V\left\{\mathrm{~N}_{5}{ }^{+}\right\}+V\left\{\mathrm{~N}_{3}{ }^{-}\right\}=$ $0.109( \pm 0.024)$. For $\mathrm{N}_{5}{ }^{+} \mathrm{N}_{3}{ }^{-}$in eqn $(10), 2 I=$ $v\left|z_{+} z_{-}\right|=2(1)(1)=2$, hence $I=1$, then (using eqn (12)): $U_{\text {POT }}\left\{\mathrm{N}_{5}{ }^{+} \mathrm{N}_{3}{ }^{-}\right\} / \mathrm{kJ} \mathrm{mol}^{-1}=2\left[\alpha / V_{\mathrm{m}}\left\{\mathrm{N}_{5}{ }^{+} \mathrm{N}_{3}{ }^{-}\right\}^{1 / 3}+\beta\right]$ with ${ }^{18}$ $\alpha=117.3 \mathrm{~kJ} \mathrm{~mol}^{-1} \mathrm{~nm}$ and $\beta=51.9 \mathrm{~kJ} \mathrm{~mol}^{-1}$, leading to $U_{\text {POT }}\left\{\mathrm{N}_{5}{ }^{+} \mathrm{N}_{3}{ }^{-}\right\} / \mathrm{kJ} \mathrm{mol}^{-1} \approx 595( \pm 31)$.

The values calculated from Hofmann's elemental volumes ${ }^{13}$ are: $V\left\{\mathrm{~N}_{5}{ }^{+}\right\} / \mathrm{nm}^{3} \approx 0.059( \pm 0.001)$ and $V\left\{\mathrm{~N}_{3}{ }^{-}\right\} / \mathrm{nm}^{3} \approx$ $0.035( \pm 0.001)$ leading to $V_{\mathrm{m}}\left\{\mathrm{N}_{5}{ }^{+} \mathrm{N}_{3}{ }^{-}\right\} / \mathrm{nm}^{3} \approx 0.094$ $( \pm 0.001)$, in broad agreement with the value above. 
The value of $S_{298}{ }^{\circ}\left\{\mathrm{N}_{5}{ }^{+} \mathrm{N}_{3}{ }^{-}\right\} / \mathrm{J} \mathrm{K}^{-1} \mathrm{~mol}^{-1} \approx 1360[0.109$ $( \pm 0.024)]+15=163.2( \pm 32.5) \cdot \Delta H / \mathrm{kJ} \mathrm{mol}^{-1} \approx$ $-1077.4( \pm 31) ; \Delta \mathrm{S} / \mathrm{J} \mathrm{K}^{-1} \mathrm{~mol}^{-1} \approx 603.1( \pm 32.5)$ so that $\Delta G / \mathrm{kJ} \mathrm{mol}^{-1} \approx-1257.2( \pm 32.4)$, indicating the massive thermodynamic instability of the material with respect to decomposition to nitrogen gas. This agrees with our experimental observations.

Other examples of the application of VBT are included in the ESI to this tutorial review: $\uparrow$ dioxygen dioxygenyl superoxide ion, $\mathrm{O}_{2}{ }^{+} \mathrm{O}_{2}{ }^{-}$; solid ammonium hydroxide, $\mathrm{NH}_{4} \mathrm{OH}(\mathrm{s})$; the formation of $\operatorname{LiSbF}_{6}(\mathrm{~s})$ and of the unknown $\operatorname{LiSb}_{2} \mathrm{~F}_{11}(\mathrm{~s})$; fluoride ion affinity (FIA) estimation; and complex solid/gas reactions: the $\mathrm{NO} / \mathrm{NO}_{2}-\mathrm{LiAl}(\mathrm{OR})_{4}$ reaction.

In attempting to apply these methods, it should always be remembered that VBT offers us only a rough guide to the underlying thermodynamics but, in cases where data is unknown, as in the above examples and those in the ESI, $\uparrow$ it serves to provide a quantitative estimate of the likely situation (but does ignore kinetic factors). Crystallographic data for many known materials may be found in extensive databases. $^{2,31}$

\subsection{Organic materials}

6.1.1 Enthalpies of condensed phases. Direct prediction of the enthalpy of formation of condensed organic phases is generally impractible and, instead, the much more accessible procedure is used of prediction of the enthalpy of formation of the gasphase molecule followed by subtraction of the enthalpy of condensation (the negative of either sublimation from the solid or vaporisation from the liquid). Many procedures are available for prediction of the gas-phase enthalpies of formation, from the simple bond energy/enthalpy summations mentioned above, to more sophisticated group contribution methods, to modern computer-based correlations. Extensive group procedures are available for prediction of enthapies of sublimation. ${ }^{17}$ These methods are very successful for members of oligomeric series, although less successful for multifunctional compounds. ${ }^{16}$

6.1.2 Entropies of organic liquids. Fig. 5 shows our relationship ${ }^{9}$ between $S_{298}{ }^{\circ}$ and $V_{\mathrm{m}}$ for organic liquids.

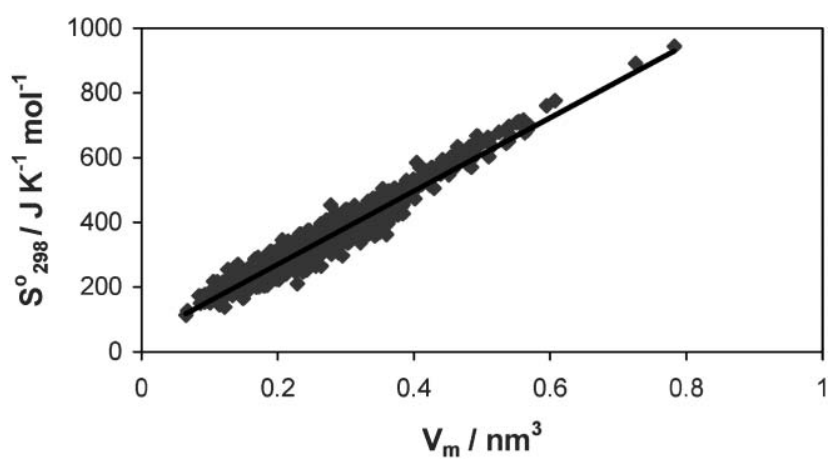

Fig. $5 S_{298} / \mathrm{J} \mathrm{K}^{-1} \mathrm{~mol}^{-1}$ plotted versus formula unit volume, $V_{\mathrm{m}}$, for 1496 organic liquids. See Table S3c in the ESI for regression parameters. $\dagger$
6.1.3 Entropies of ionic liquids. These equations have recently been adapted to application for ionic liquids. ${ }^{32}$

\subsection{Covalency}

When covalent forces come more prominently into play, so that the coulombic forces are not absolutely dominant, then the above equations become increasingly unreliable. Work is currently proceeding with the aim to improve further our predictive methods in such circumstances, by strengthening the theoretical basis.

\section{Group methods}

Group methods for thermodynamic prediction are many and varied, ranging from simple addivity of group contributions (such as of group volumes to generate density ${ }^{33}$ ) to complex, computer-based schemes ${ }^{34}$ which require structural insight in order to select best groups and appropriate interactions. If the simple first order relations discussed above are unsuitable, then resort to these more complex procedures becomes necessary.

\section{References}

1 D. D. Wagman, W. H. Evans, V. B. Parker, R. H. Schumm and R. L. Nutall, Selected Values of Chemical Thermodynamic Properties, National Bureau of Standards, Washington, DC, 1982; M. W. Chase, Jr., et al., J. Phys. Chem. Ref. Data, Monogr., 1998, 9, 1; NIST database: http://www.webbook.nist. gov/chemistry/.

2 Handbook of Chemistry and Physics, ed. D. R. Lide, CRC Press: Boca Raton, FL, 85th edn, 2004-2005; Handbook of Chemistry and Physics on CD-ROM, Version 2005, ed. D. R. Lide, CRC Press: New York, 2005.

3 D. R. Stull, E. F. Westrum, Jr. and G. C. Sinke, The Chemical Thermodynamics of Organic Compounds, Wiley, New York, 1969; B. E. Poling, J. M. Prausnitz and J. P. O'Connell, The Properties of Gases and Liquids, McGraw-Hill, New York, 5th edn, 2001, and references therein.

4 See, for example: K. A. Peterson, S. S. Xantheas, D. A. Dixon and T. H. Dunning, Jr., J. Phys. Chem. A., 1998, 102, 2449-2454, or ref. 15 , footnote (1) for other references.

5 O. Kubaschewski, C. B. Alcock and P. J. Spencer, Materials Thermochemistry, Pergamon, Oxford, 6th edn, 1993; P. J. Spencer, Thermochim. Acta, 1998, 314, 1-21.

6 See S. W. Benson, Thermochemical Kinetics, Wiley, New York, 2nd edn, 1976.

7 M. S. Westwell, M. S. Searle, D. J. Wales and D. H. Williams, J. Am. Chem. Soc., 1995, 117, 5013-5015.

8 H. D. B. Jenkins and L. Glasser, Inorg. Chem, 2003, 42, 8702-8708.

9 L. Glasser and H. D. B. Jenkins, Thermochim. Acta, 2004, 414, $125-130$.

10 H. D. B. Jenkins and L. Glasser, Inorg. Chem., 2002, 41, 4378-4388.

11 H. D. B. Jenkins and L. Glasser, J. Am. Chem. Soc., 2004, 126, 15809-15817.

12 C. H. Yoder and N. J. Flora, Am. Mineral., 2005, 90, 488-496.

13 D. W. M. Hofmann, Acta Crystallogr., 2002, B57, 489-493.

14 Y. Marcus, H. D. B. Jenkins and L. Glasser, J. Chem. Soc, Dalton Trans., 2002, 3795-3798.

15 H. D. B. Jenkins, L. Glasser, T. M. Klapötke, M.-J. Crawford, K. K. Bhasin, J. Lee, G. J. Schrobilgen, L. S. Sunderlin and J. F. Liebman, Inorg. Chem., 2004, 43, 6238-6248.

16 T. E. Daubert, J. Chem. Eng. Data, 1996, 41, 942-946.

17 J. S. Chickos and W. E. Acree, Jr., J. Phys Chem. Ref. Data, 2003, 32, 515-878.

18 H. D. B. Jenkins, H. K. Roobottom, J. Passmore and L. Glasser, Inorg. Chem., 1999, 38, 3609-3620. 
19 H. D. B. Jenkins, D. Tudela and L. Glasser, Inorg. Chem., 2002, 41, $2364-2367$.

20 D. A. Dixon, D. Feller, K. O. Christe, W. W. Wilson, A. Vij, V. Vij, H. D. B. Jenkins, R. M. Olson and M. S. Gordon, J. Am. Chem. Soc., 2005, 126, 834-843.

21 H. D. B. Jenkins, J. Chem. Educ., 2005, 82, 950-952.

22 W. E. Dasent, Inorganic Energetics - An Introduction, Cambridge University Press, Cambridge, 2nd edn, 1982; D. A. Johnson, Some Thermodynamic Aspects of Inorganic Chemistry, Cambridge University Press, Cambridge, 2nd edn, 1982.

23 Y. Marcus, Ion Properties, Marcel Dekker, New York, 1997.

24 A. F. Kapustinskii, Q. Rev. Chem. Soc., 1956, 10, 283-294.

25 L. Glasser, Inorg. Chem., 1995, 34, 4935-4936.

26 L. Glasser and H. D. B. Jenkins, J. Am. Chem. Soc., 2000, 122, 632-8.

27 I. Krossing, J. Passmore and H. D. B. Jenkins, J. Fluorine Chem., 2004, 125, 1585-1592.
28 D. R. Rosseinsky, L. Glasser and H. D. B. Jenkins, J. Am. Chem. Soc., 2004, 126, 10473-10477.

29 H. D. B. Jenkins, J. Solution Chem., 1993, 22, 1029.

30 A. Vij, W. W. Wilson, V. Vij, F. S. Tham, J. A. Sheehy and K. O. Christe, J. Am. Chem. Soc., 2001, 123, 6308-6313.

31 J. D. H. Donnay and H. M. Ondik, Crystal Data: Determinative Tables, National Bureau of Standards, Washington, DC, 3rd edn, 1973; Crystallographic and Crystallochemical Database for Mineral and their Structural Analogues, Institute of Experimental Mineralogy, Chernogolovka, http://database.iem.ac.ru/mincryst/.

32 L. Glasser, Thermochim. Acta, 2004, 421, 87-93; Q. G. Zhang, J. Z. Yang, X. M. Lu, J. S. Gui and Z. Huang, Fluid Phase Equilib., 2004, 226, 207-211; J. Z. Yang, X. M. Lu, J. S. Gui and W. G. Xu, Green Chem., 2004, 6, 541-543.

33 G. Piacenza, G. Jacob and R. Gallo, Adv. Quant. Struct.-Prop. Relat., 2002, 3, 67-107.

34 M. Shacham, N. Brauner, G. St. Cholakov and R. P. Stateva, AIChE J., 2004, 50, 2481-2492. 